\title{
Ibn Sīnā on reductio ad absurdum
}

\author{
Wilfrid Hodges \\ Herons Brook, Sticklepath, \\ Okehampton, Devon EX20 2PY, England \\ wilfrid.hodges@btinternet.com
}

This paper studies the analysis of reductio ad absurdum by Ibn Sīnā (known to the Latin West as Avicenna), who was born in 980 in a village near the Bactrian town of Balkh on the Silk Road, and died in 1037 after a career spent moving around within the present boundaries of Iran.

References to Ibn Sīnā's writings are to his Arabic texts listed in the bibliography, and are given in the format page.line. References to the text translated from Qiyās [14] at the end of this paper are marked with an asterisk *.

\section{The argument form in question}

We should start with what Ibn Sīnā calls the 'usual' (' $\bar{a} d a)$ form of proof by reductio ad absurdum (Qiyās [14] 410.13^). He gives an example at (38) below:

Not not every $C$ is a $B$

(1)

Every $C$ is a $B \quad$ Every $B$ is an $A$

$$
\frac{\text { Every } C \text { is an } A}{\frac{\perp}{\text { Not every } C \text { is a } B}} \quad \text { (Not every } C \text { is an } A \text { ) }
$$

Ibn Sīnā's description omits the premise 'Not every $C$ is an $A^{\prime}$. But we can see that it is needed in order to get a contradiction from 'Every $C$ is an $A^{\prime}$, and in fact Ibn Sīnā does include the premise in his fuller analysis at (26).

This is only one example. Ibn Sīnā was certainly well aware that reductio arguments can include many more steps than this. So it seems reasonable to assume that the syllogism from 'Every $C$ is a $B^{\prime}$ and 'Every $B$ is an 
$A^{\prime}$ to 'Every $C$ is an $A^{\prime}$ is proxy for an arbitrarily complicated derivation, for example a derivation of $\chi$ from $\phi$ and a set of assumptions $\Psi$. Also Ibn Sinna gives the form for proving a negated conclusion, and this allows him to remove a double negation at the top of the derivation. If the conclusion was not negated this step would be missing. So we have two general forms:

$(2)$

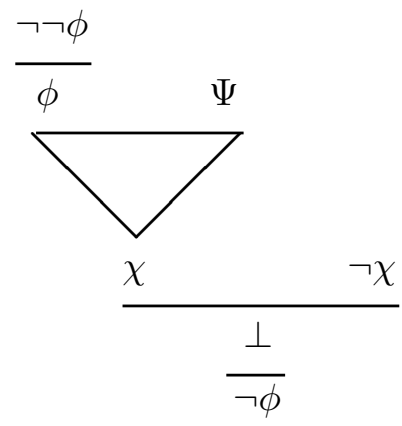

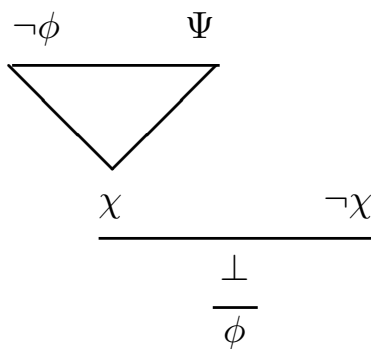

In modern formalisms we would mark that the assumption at top left is cancelled at the bottom step. But Ibn Sīnā had no conscious notion of cancelling assumptions. I have no idea whether any logician or mathematician of that date or earlier mentions any such notion; certainly I never came across it.

The double negation at top left deserves some discussion. Probably Ibn Sinnā wrote it that way because he reckoned that a reductio argument normally begins by assuming that something is false. But in any case he had no problems with deducing $\phi$ from $\neg \neg \phi$. Not all logicians of his date had a sentence negation operator. But Arabic has one built in: laysa, which means 'It is not', and 'It is not the case that' at the beginnings of sentences. For safety I add that Ibn Sīnā's logic was a natural language logic, and with natural languages we always find some glitches. In the case of laysa there are some subtleties about scope when laysa is followed immediately by an existential quantifier, as Ibn Sīnā himself often points out with examples. But for present purposes that's a side issue.

On page 308 of the otherwise very excellent Oxford Handbook of Medieval Philosophy [21] Chris Martin remarks that Ibn Sīnā 'seems not to ... note the possibility that [sentence negation] might be iterated'. In fact Ibn Sīnā explicitly iterates laysa at Qiyās [14] 93.13 and at Burhān [15] 190.15, and in both places he says that the double negation can be dropped. (See also Najāt [17] 30.12.) The manuscript text at Qiyās [14] 410.13^ needs correction, but almost certainly it should read laysa laysa kullu; here laysa laysa is unambiguously an iterated sentence negation, and presumably it can be followed by an arbitrary sentence. Ibn Sīnā is saying precisely that this double laysa 
can be dropped. A moral is that one should never draw conclusions about Ibn Sīnā's logic from his work Išārāt [19] alone; it's too selective and quirky. But the fact that the one statement about Ibn Sīnā's logic in [21] is dubious speaks volumes about the state of scholarship in this area. We are still seriously short of commented translations of key texts.

\section{Ibn Sīnā's analysis of the argument}

Ibn Sīnā believes that when people write the argument (2) above, they normally mean something different. This is an example of a very general claim he makes, that we almost always mean more than we say, and that one task for logicians is to make explicit what we leave unspoken. We come back to this in section 4 below.

According to Ibn Sīnā, the assumption $\neg \neg \phi$ in the lefthand version of (2) carries through as far as $\chi$, though it is normally not re-stated after it has first been introduced. So when we write $\chi$, we really mean $(\neg \neg \phi \rightarrow \chi)$ (as he says at Qiyās [14] 410.14f $\mathrm{f}^{\star}$ ). Presumably the assumption $\neg \neg \phi \rightarrow$ has to be added at all steps of the derivation that depend on the initial $\neg \neg \phi$. At top left this allows us to replace the derivation of $\phi$ from $\neg \neg \phi$ by a single formula: $(\neg \neg \phi \rightarrow \phi)$ (as he gives it at (23)). The 'impossible absurdity' represented by $\perp$ now resolves into a derivation of $\neg \phi$ from $(\neg \neg \phi \rightarrow \chi)$ and $\neg \chi$. This and analogous adjustments of the righthand version of the argument transform (2) into:
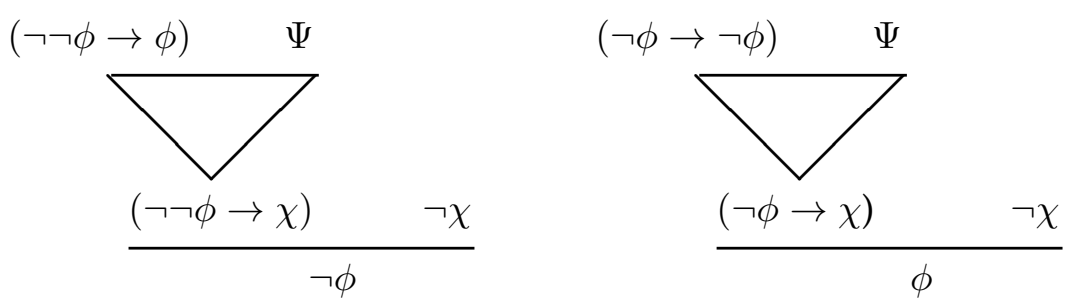

For convenience we can call (2) the surface forms and (3) the deep forms.

The passage from the surface to the deep form has two main effects, both of which Ibn Sīnā must have intended. The first is that there is no longer any issue of making assumptions; the entire derivation can be read as deductions from given facts. The second is that there are no longer any inferences from two contradictory premises $\chi$ and $\neg \chi$. Later we will discuss the reasons why Ibn Sīnā will have welcomed these effects. 


\section{What is logic?}

We will need some facts about Ibn Sīnā's understanding of logic as a whole. This section and the next will summarise some of his main views; I have to ask the reader to take rather a lot on trust.

Logic is about meanings. More precisely it studies two main things about meanings. The first is how meanings can correctly be combined into compound meanings. The second rests on the fact that some meanings are sentence meanings, so that we can ask whether these meanings are 'known to be true'. Logic studies the correct rules which allow us to come to know the truth of a sentence meaning by deducing that meaning from the meanings of other sentences already known to be true. (Easterners [18] pp. 9f.)

Logic is not a device for introducing a new kind of mental activity. We do already combine meanings into compound meanings, and we do already deduce things from other things. Logicians aim to regulate these activities and verify that they have been carried out correctly; this kind of verification is called analysis. To do their job properly, logicians need to understand how humans do normally combine meanings and deduce things. Often a good way of describing a rule is to say what what would count as applying the rule correctly.

In fact humans don't operate directly on meanings. Meanings are too intangible, and humans need to represent them symbolically in order to keep track of the patterns formed by their combinations. (Ibn Sīnā says this at Madkal [13] 22.18, referring to the tartīb - internal structure, patterning - of meanings.) This is one of the main functions of language; in fact we need language just as much for reasoning in our own minds as we need it for communicating with each other.

Human minds have a piece of dedicated machinery, which Ibn Sīnā calls the $b \bar{a} l$, for processing strings of symbols so as to perform deductions. For example one activity of the $b \bar{a} l$ which he mentions in a number of places is the following. Two sentences are fed into the $b \bar{a} l$ one after the other, and the $b \bar{a} l$ scans them to see whether there are any common elements between the two sentences. The $b \bar{a} l$ does this best, he claims, if the common element appears near the end of the first sentence and near the beginning of the second. At Qiyās [14] 410.2* below he suggests a name for this activity of finding common elements: id $\bar{g} \bar{a} m$. The name comes from linguistics and refers to the way in which similar sounds at the end of one word and the beginning of the next can be combined. (I translated it 'unification', taking a term from modern logic. You can find out more about $i d \bar{g} \bar{a} m$ by going to the internet and looking up the procedures of Qur'anic recitation.) 
For some inferences, the $b \bar{a} l$ performs unification, cuts out the unified parts and recombines the remaining pieces of the sentences into a new sentence, which it outputs as conclusion. Ibn Sīnā describes inferences that work this way as 'recombinant' (iqtirānī). An example of a recombinant inference appears inside (1) above: the inputs are 'Every $C$ is a $B$ ' and 'Every $B$ is an $A^{\prime}$, unification finds $B$ in both sentences, and the remaining pieces are reassembled as 'Every $C$ is an $A^{\prime}$. This illustrates one of the standard Aristotelian non-modal syllogistic moods. Ibn Sīnā calls syllogisms in these moods 'predicative' (hamlī), because they use only the standard 'predicative' sentence forms 'Every $B$ is an $A^{\prime}$, 'Some $B$ is an $A^{\prime}$, 'No $B$ is an $A^{\prime}$, 'Not every $B$ is an $A^{\prime}$. Every predicative syllogism is a recombinant inference, but Ibn Sīnā believes that the description in terms of unifying and recombining applies to some other kinds of inference too.

Ibn Sinna notes that there are some valid inferences that are not recombinant. For example there is modus ponens; the conclusion of an application of modus ponens is not assembled from parts of both premises. Instead one premise is simply a duplicate (possibly negated) of part of the other premise, and then the conclusion is made out of what remains of the other premise (again possibly negated). Inferences of this kind are called 'duplicative'. The occurrences of modus tollens at the bottom of the inferences (3) are examples of duplicative inferences.

\section{Internal structures of propositions}

This section continues to report Ibn Sīnā's general views on language and logic.

Clearly the $b \bar{a} l$ will need to operate on the syntactic structures of the sentences fed into it. The syntactic structure of a sentence reflects the underlying structure of the compound meaning of the sentence; in short, syntax reflects semantics. But the semantics is more basic, since it is uniform across what Ibn Sīnā calls 'possible languages', whereas syntax can vary greatly from one language to another.

Ibn Sīnā says enough about sentence structure to allow us to build up a reasonably detailed picture; see for example [11]. He is talking about natural language, and the kinds of structure that he finds will be familiar to linguists. Briefly, a simple sentence meaning has two main parts, a noun meaning and a verb meaning. There is a third element of meaning whose primary role is to distinguish noun from verb. The rest of the simple sentence meaning consists of other meanings that are attached to one or other 
of these three elements. For example there is often a quantifier meaning attached to the noun meaning. Sentence negation and modality tend to attach to the 'third element'. Compound sentence meanings can be formed by attaching other elements to the sentence meaning as a whole.

Probably the most distinctive feature of Ibn Sīnā's logic is the role that he gives to the 'attached' elements. He has various names for them; one of the most general is 'conditions' (šurūt). Language is finite, but the range of things we may want to say is completely open-ended. Often we can build up the meanings that we need by making attachments. But for practical purposes this is not always necessary - in many cases we leave the attachments unstated, leaving them to be recovered from the context. That context includes the normal usage $\left({ }_{i s t i}{ }^{c} m \bar{a} l,{ }^{c} \bar{a} d a\right)$ of the relevant speech community.

Ibn Sīnā raids Aristotle's treatments of sophistical fallacies for examples of unstated attachments where we could have saved ourselves from error by making them explicit. But he finds this a thoroughly unsatisfactory source of examples: more or less by definition, Aristotle presents cases where the normal linguistic procedures have gone wrong. ('I very much dislike examples that misuse language in this kind of way', says Ibn Sīnā at Safsata [16] 14.10.) In fact he thinks it is scandalous that Aristotelian logicians completely ignore the use of attachments in normal scientific discourse. A fortiori Aristotelian logic has nothing to say about rules of inference that involve these attachments. Thus it has virtually nothing to say about multiple quantification, or about relations. (Though truth to say, it's not at all clear where Ibn Sīnā himself thinks the extra quantifiers should be attached.)

In Ibn Sīnā's time there was a distinction between two schools of Qur'anic exegesis. The Zāhirists believed that the language of the Qur'ān should be taken at face value; how dare we interfere with what God has chosen to say to us? The Bātinists believed by contrast that all language has explicit and implicit features, and a serious appreciation of the Qur'ān has to undertake to reveal the implicit features in the text. Today's Salafists are in some sense successors to the Zāhirists, while successors of the Bātinists are more likely to be found in Shi'a Islam. Qur'anic exegesis is only a very minor element in Ibn Sīnā's logic, but the Zāhirist/Bātinist distinction can be read as a disagreement about language in general. So it's revealing that Ibn Sīnā several times describes his logical opponents as Zāhirists (Najāt [17] 12.14, Burhān [15] 52.11, Easterners [18] 36.12).

In the case of reductio arguments, the main suppressed element is the repetitions of the assumption 'If it is false that not $p \ldots$ '. What kind of 
evidence could Ibn Sīnā have had in mind to show that Arabic scientists suppressed repeated assumptions in this way? We needn't look far for an answer. Here for example is a literal rendering of a standard medieval Arabic text of Proposition 27 of Euclid Elements I:

When a straight line lies across two straight lines so that the two symmetrically-opposite angles are equal then the two lines are parallel.

Demonstration: If the two are not parallel then when they are both extended on one of the two sides, they meet. So we extend them on the side $B D$ so they meet in a point $K$ if that is possible, so the angle $A H T$ external to the triangle $K T H$ is greater than the internal angle $K T H$, as was proved in the demonstration of 16 of $\mathrm{i}$, and this is absurd. (Codex Leidensis [2] 114-116)

The reductio assumption is introduced at the beginning of the Demonstration with an 'If' ('in) rather than a 'suppose' (li-yakun). As Ibn Sīnā says, this assumption is not repeated anywhere, but we can see that it's followed by a succession of steps and a change of sentence. Similar examples are easy to find.

\section{Ibn Sīnā's method of analysis}

Ibn Sīnā describes in his Autobiography how he proceeded when he used the tools of logic to check arguments. It's widely recognised that Ibn Sīnā is setting himself up as a paradigm here, not just describing facts about his past life. So the details matter.

I compiled a set of index cards for myself (literally 'between my hands'), and for each argument that I examined, I entered into the cards its syllogistic premises, their internal structure (tartīb), and what might follow from them. I took care of the conditions of its premises, until I had verified the point at issue. (Autobiography [20] pp. 26, 28; [6] pp. 27, 179)

This translation combines the best features of the translations of Gohlman and Gutas. The text itself makes clear that Gutas is right (against Gohlman) in thinking that $t a r t i \bar{b}$ is about the structure of the premises, not the classification of syllogisms. But there was no need for Gutas to emend tartī $b$ to tarki $b$, given what we have already noted about the meaning of tartī $b$. 
In (5) we have an outline of a methodology for analysis. Faced with a purported argument, we start the process of checking it by finding the propositions involved, and analysing them down to their structure. When the inner semantic structure of the propositions has been established, we can separate out the core of predicative propositions by identifying the noun, verb and quantifier, and the presence or absence of negation. We can then apply Aristotle's predicative syllogistics to tell whether the resulting stripped-down argument is 'productive' (i.e. valid). If it isn't, Ibn Sīnā reckons that a fortiori the original argument will not be valid either. (For example Qiyās [14] 325.8f.) The task of checking validity for predicative syllogisms is completely algorithmic.

If the stripped-down argument survives this test, the next step is to restore all the attachments that we stripped off, and see whether the validity survives. Ibn Sīnā describes this as 'taking care of the conditions' (murāa $\bar{a} t u$ l-šurūt); this phrase and variants of it appear often in Ibn Sīnā's writings, not only in logic. Since the class of possible conditions and attachments is open-ended, there is no prospect of having an algorithm that covers them all. In any case Ibn Sīnā clearly has no idea how one could prove the correctness of such an algorithm. So what can he do?

\section{A methodology for going beyond Aristotle}

Some points of method should be clear from what has already been said. The logician can't hope to analyse an inference if he or she doesn't know exactly what inference was intended. So it's essential to establish the suppressed but intended meanings as well as the explicit ones. For this a logician needs to be thoroughly familiar with the habits and conventions of the community in which the inference was produced. This is a matter of knowing the habits and conventions, not of following them. In fact when we make suppressed meanings explicit, we are precisely not following the community's usage.

Next, once we have settled what was meant, we need to put the minimum possible distance between ourselves and those meanings. Ibn Sīnā sometimes speaks of having the required meanings 'in our hands'. In (5) we saw him writing down the internal structures of the premises on index cards 'in his hands'. At Qiyās [14] 150.14 he attacks a certain procedure because it makes you 'abandon what you had in your hands'; it's revealing to see what this procedure was. The procedure involved asking whether a certain proposition was true in a certain situation. But, says Ibn Sīnā, the 
proposition

(6) $\phi$ is true in situation $S$.

is a more complicated proposition than $\phi$ was. So if the logical properties of $\phi$ were not clear to start with, how can we hope to understand the logical properties of (6)? This argument suggests a global ban on metalogic.

The two quotations below endorse the point that an analysis of reductio arguments should stay at the level of the arguments themselves and not add new material.

... there is no need for any contrived and elaborate explanation, rounding it out with goodness knows how many syllogisms, in order to give an analysis of the complete form of the syllogism of absurdity. There is no need for the kind of lengthy exposition of [this syllogism] that one finds in the textbooks. (Qiyās [14] 408.9$\left.11^{\star}\right)$

All of these kinds of mutilation, and [these] things that are hidden and not explicit, lengthen the discussion but give us no new information. [By contrast] the account we have given is exactly the absurdity syllogism itself, no more and no less. (Qiyās [14] $\left.410.9-11^{\star}\right)$

The claim that Ibn Sīnā gives 'exactly the absurdity syllogism itself, no more and no less' is exaggerated, but we can see a grain of truth. The only changes that he makes are to bring to the surface a feature that was always intended. He adds no notions that are not in the intended argument itself.

Though he doesn't mention the point, I think we can infer that he would have used the same argument to condemn attempts to understand reductio ad absurdum in terms of a dialogue. For example De Morgan tells us:

The form in which Euclid argues, supposes an opponent; and the whole argument then stands as follows. "When $\mathrm{X}$ is $\mathrm{Y}$, you grant that $\mathrm{P}$ is $\mathrm{Q}$; but you grant that $\mathrm{P}$ is not $\mathrm{Q}$.

(9) I say that $X$ is not $Y$. If you deny this you must affirm that $\mathrm{X}$ is $\mathrm{Y}$, of which you admit it to be a consequence that $\mathrm{P}$ is Q. But you grant that $\mathrm{P}$ is not $\mathrm{Q}$; therefore" (etc. etc.) ([1] p. 5)

This seems a classic example of a 'contrived and elaborate explanation'. 
We know another thing that Ibn Sīnā certainly regarded as a barrier between our minds and the problem at hand. That is the use of artificial languages, or artificial conventions within our own language. (E.g. Qiyās [14] p. 45.) In particular he believed that the artificial language used by other Aristotelian logicians helped to hide from them the richness of meanings expressible in natural language; it was part of the scandal of Aristotelian logic that he aimed to expose. This makes him a very different kind of logician from the later Scholastics with their formalised Latin, or from Frege with his rigidly defined Begriffsschrift.

The points we have made here are largely negative, but they have a positive core that we will be able to expand below. To check that an inference is valid, where we have no calculus available to help us, our best hope is to sink ourselves in the inference and trust to our intuitions. As in any human science, we improve our grasp by repeating the move with a range of examples.

There is one major reservation that Ibn Sīnā makes to the general embargo on adding new ideas to the material being analysed. It has nothing specifically to do with reductio ad absurdum, but I should mention it because of its fundamental importance in Ibn Sīnā's general theory of logic. Ibn Sīnā observes that a logician has to use notions like

Meaning $M$ occurs at position $P$ in meaning structure $S$.

(For example ' $M$ occurs as subject in proposition $P^{\prime}$.) He takes the view that notions like (10) have to be bundled in with each separate meaning so as to make meanings accessible to logic. This approach makes some sense if you think in object-oriented terms with the meanings as objects. In those terms, Ibn Sīnā is saying that for purposes of logic, notions like (10) have to be added to the objects as 'methods'. A garbled version of this theory reached the Western Scholastics in the form of the doctrine that the subject of logic is 'second intentions'. The Scholastic doctrine seems to be largely the result of trying to understand Ibn Sīnā by reading Al-Fārābī and Ibn Rushd (Averroes) instead.

\section{Why is the deep form valid?}

Suppose we apply Ibn Sīnā's methods to analyse an argument by reductio ad absurdum. How will it go? One of the first steps will be to establish the intended structure of meanings. This is precisely what Ibn Sīnā reckons he 
has done with the deep form (3). Then given that structure, we need to test whether the inference steps in it are valid.

The modus tollens argument at the bottom of the derivation creates no problems. By Ibn Sīnā's time this was a well-accepted form of argument; Ibn Sīnā discusses it in detail at Qiyās [14] 395.8, under the name of the 'fourth standard duplicative mood'.

It's just as well for Ibn Sīnā that his deep form removes the inference step

$$
\chi, \neg \chi \vdash \perp
$$

at the bottom of the surface form. At Qiyās [14] 547.13f he claims that the $b \bar{a} l$ is incapable of accepting inputs of the form $\chi, \neg \chi$. We needn't read him as saying that (11) is an invalid inference. More likely his point is that there doesn't seem to be any way of reading (11) as a real-life inference. Faced with premises $\chi$ and $\neg \chi$, our first reaction is to detach ourselves from the premises and observe that the two propositions are incompatible.

There is a problem with the formula at top left: $(\neg \neg \phi \rightarrow \phi)$ or $(\neg \phi \rightarrow$ $\neg \phi)$. We know that Ibn Sīnā regarded the first formula as expressing a true principle, and he could hardly have said less for the second one. But for Aristotelians there was an issue, that Aristotle had said that the conclusion of a syllogism should be something 'different from' the premises. If $(\neg \phi \rightarrow \neg \phi)$ is going to be used so as to replace $\neg \phi$ in some other formula by $\neg \phi$, then nothing 'different' will have been proved. Ibn Sīnā discusses the question at Qiȳas [14] 69.13, in connection with what he calls an 'ugly example':

If there is movement then there is movement;

there is movement.

Hence there is movement.

His preferred response is that if the conclusion of a syllogism has to be 'something different', then this example is not a syllogism. But he is perfectly happy to say that there are valid arguments that are not syllogisms; for example all valid one-premise arguments.

There remains the bulk of the derivation; it consists of a derivation supposedly already known to be valid, but augmented by attaching an assumption of the form 'If $p$ then ...' all the way down one branch. So at each inference step on that branch we have a task of 'taking care of the conditions'. In the passage translated below, Ibn Sīnā gives no hint of how we should do this. But in fact he has already devoted two whole sections of Qiyās, vi.4 and vi.5, to a closely related question. 
We can formulate the question as follows. Consider an operation $\delta(-)$ that takes formulas to formulas. For which such operations $\delta$ do we have the following principle?

$$
\eta, \Psi \vdash \theta \Rightarrow \delta(\eta), \Psi \vdash \delta(\theta)
$$

In vi.4 he claims that the principle (13) holds if the inference $\eta, \Phi \vdash \theta$ is any of the standard Aristotelian categorical syllogistic moods and $\delta$ is either of the following two operations:

$$
\begin{aligned}
& \delta(\psi)=\forall t(\phi \rightarrow \psi) . \\
& \delta(\psi)=\exists t(\phi \wedge \psi) .
\end{aligned}
$$

For this claim to be sensible, we have to suppose that the formulas $\phi$ and $\psi$ may carry an unquantified variable $t$. In fact Ibn Sīnā believed that if $\phi$ and $\psi$ are scientific statements then this is very often the case, with $t$ a variable over times or situations. But his reasons for believing this are not relevant here. We should ask instead how he justifies his claim.

He aims to show that his claim is true by explaining how we can convince ourselves of it in particular cases. Here is a typical example (Qiyās [14] 327.13-17); he gives many examples along the same lines.

Whenever $r$, then every $C$ is a $D$;

and no $A$ is a $D$.

So whenever $r$, then no $C$ is an $A$.

It can be demonstrated by converting the predicative premise. It can also be demonstrated as follows:

Whenever $r$, then $C$ is a $D$;

and no $A$ is a $D$.

But whenever $C$ is a $D$ and no $A$ is a $D$, then no $C$ is an $A$.

It entails: Whenever $r$, then no $C$ is an $A$.

This calls for some background. All the argument moods in Qiyās vi.4 are got by taking a valid predicative syllogistic mood and applying one of the above operations $\delta$ as in (13) and (14), where $\eta$ can be either the first or the second premise. So $\Psi$ consists of the other premise, which stays unchanged; Ibn Sinnā calls it the 'predicative premise'. In the example above, the underlying predicative mood is Cesare.

He offers two justifications of the argument form (15). The first is 'by converting the predicative premise'. This means: use the fact that 'No $A$ is a 
$D$ ' says the same as 'No $D$ is an $A^{\prime}$. That changes the underlying predicative mood to Celarent; Ibn Sīnā has already considered this case at Qiyās [14] 326.12, where he considers it too trivial to deserve a detailed explanation.

The second justification is more useful to us. This appears as the argument (16). The first two lines of the argument simply repeat the premises of (15). The third line is a third premise, namely the mood Cesare written as an implicative formula. Ibn Sīnā often uses universal quantification over times or situations to indicate a necessary truth; the conclusion of Cesare follows necessarily from its premises. The fourth line is the conclusion of (15). So essentially all that Ibn Sīnā has done in (16) is to remind us of the underlying predicative syllogism.

What does he expect us to do with (16)? The conclusion doesn't follow from the three premises by any obvious sequence of rules that Ibn Sinnā has already described. Does he expect us to invent the rules? It would probably be a different sequence of rules for each underlying predicative syllogism. So it seems very unlikely that he expects this.

A more plausible answer is that he wants us to check that we believe Cesare, and then in the light of that, check that we find it convincing to add the prefix 'Whenever $r$ ' to one premise and the conclusion of Cesare. In other words, this is an appeal to intuition, strengthened by the fact that he expects us to check the same intuition in a lot of different cases.

Tarski was still using essentially the same approach in 1931 for a specific purpose which he describes as follows:

Si nous désirons acquérir la certitude subjective de la justesse matérielle de la déf. 10 et de sa conformité à l'intuition, sans sortir du domaine des considérations strictement mathématiques, nous sommes contraints de recurrir à la voie empirique. (Tarski [22] p. 229)

Briefly, Tarski wants to describe how we can come to accept a metamathematical principle with 'subjective certainty', using only methods from mathematics. Ibn Sīnā wants to bring us to subjective certainty in relation to a principle about inferences, using only the inferences themselves. In practice Tarski and Ibn Sīnā do pretty much the same thing: they both invite us to sample a number of instances and check that we are convinced that the higher-level principle is true of each instance that we sample. Tarski distinguishes this approach as 'empirical'; Ibn Sīnā has no special name for it because he rejects any other approach. (See [8] pp. 98, 111f for more comments on Tarski's 'voie empirique'.) 
Whether or not Ibn Sīnā was relying on an 'empirical' approach in this sense, he certainly believed that (13) represented an acceptable logical rule, at least for the operations $\delta$ in (14). Of course it's possible that he believed that they only work when applied to predicative syllogisms, though he never suggests this and there is no obvious reason why this restriction should apply. The derivations in (3) use a slightly different $\delta$, namely

$$
\delta(\psi)=(\phi \rightarrow \psi) .
$$

Actually Ibn Sīnā is not at all systematic in distinguishing between 'Whenever' and 'If'. But in any case it's intuitively plausible that if the more complicated operations in (14) work, then so does this simpler one.

\section{On Ibn Sīnā's proof principle}

I leave it to the reader to check that the following principle holds for firstorder sequents in any standard calculus:

Suppose $T$ a set of formulas and $\eta, \theta$ are formulas. Let $\delta(p)$ be a first-order formula containing a propositional variable $p$ which occurs only positively in $\delta(p)$ and doesn't occur in the scope of any quantifier on a variable free in some formula of $T$. If $T, \eta \vdash \theta$ then $T, \delta(\eta) \vdash \delta(\theta)$.

If Ibn Sīnā had understood quantifier scopes (which he quite certainly didn't, cf. [12]), he could have applied this principle to his examples by insisting that any time variables in the 'predicative premise' use a different letter from $t$. He did anyway believe that special steps need to be taken if we want 'indeterminates' to correlate between different propositions. But one among several reasons for not ascribing the principle (19) to Ibn Sīnā himself is that he seems to have no understanding of positive and negative occurrences. This comes to light in several ways. First, Ibn Sīnā totally lacks anything like the rules of distribution; these notions, which became popular and influential in the West, rest on the distinction between positive and negative occurrences. Second, in Qiyās vi.5 he tries to apply (13) to some kinds of operation $\delta$ where the positivity condition fails. For example he has a stab at making (13) work with

$$
\delta(\psi)=\forall t(\psi \rightarrow \phi) .
$$

Of course this is hopeless without strong ad hoc assumptions, which he duly provides. 
In some notes on the web [10] I proved a completeness theorem for a first-order calculus where the principle (19) does most of the hard work.

\section{Not considered here}

In these notes I concentrated on clarifying Ibn Sīnā's analysis of reductio arguments and putting it into context within his own works. This has left no space for the following, which somebody (not necessarily me) should look at.

1. Comparison with Frege. Ibn Sīnā's analysis has a remarkable amount in common with Frege's analysis of reductio ad absurdum in his 'Logik in der Mathematik' ([5] p. 265), and Frege's treatment of assumptions and their resolution in his 'Grundlagen der Geometrie' ([4] pp. 379-381). But the aims of the two logicians were certainly not all the same.

2. Who is under attack? Ibn Sīnā's section mentions three other approaches to analysing reductio arguments, and rejects them. There are indications that the third approach may be Al-Fārābī's, not necessarily reported fairly. There is a curious point here, that both Aristotle and Ibn Sīnā himself in their treatments of modal syllogisms seem to make exactly the mistake that Ibn Sīnā condemns in this author. I have no idea where the other two approaches come from.

3. Nonmonotonicity. At Qiyās [14] p. 240 Ibn Sīnā observes that counterfactual arguments have a kind of nonmonotonicity, in the sense that some counterfactual assumptions make it unreasonable to draw consequences from some known facts. He is aware that this causes a problem for reductio ad absurdum in scientific contexts, and he suggests that scientists can put a sort of mental clamp on statements to prevent them being overruled by counterfactual assumptions (Qiyās [14] 274.13). The details need to be clarified. So does the relationship to the Western Obligationes. Ibn Sīnā has some further discussions of reductio ad absurdum, but so far I have found nothing interesting in them.

4. The logical strength of (19). The fact that we can build a complete first-order calculus around the principle (19) indicates that this principle manages to break through several logjams that obstructed the progress of Aristotelian logic. For example by iterating it we can apply logical manipulations at any syntactic depth within a formula. Notoriously this was impossible in Aristotelian calculi ([9]). It may be significant that in Grundgesetze I [3] $\S 14$ Frege observes (in our notation) that modus ponens $(\psi \rightarrow$ 
$\chi), \psi \vdash \chi$ generalises to $\delta(\psi \rightarrow \chi), \psi \vdash \delta(\chi)$ where

$$
\delta(p)=\left(\phi_{1} \rightarrow\left(\phi_{2} \rightarrow \ldots \rightarrow\left(\phi_{n} \rightarrow p\right) \ldots\right)\right.
$$

Also the use of (19) to cover the making and resolving of assumptions shows how it can bypass the 'local formalising' tendencies of Aristotelian logic ([9] again).

\section{Translation of Ibn Sīnā, Qiȳās viii.3}

This translation follows the Cairo text, except for textual emendations recorded in the notes that follow. The paragraph numbering is mine. I am very much in debt to Amirouche Moktefi who checked and improved the translations, but any errors should be blamed on me.

viii.3 Proof by contradiction

[8.3.1] The syllogism of absurdity is really a compound syllogism formed 408.4 from just two propositional syllogisms. Thus, if the goal is a predicative proposition - this is the case which is investigated in the [Prior] Analytics - then the conclusion is this predicative [proposition]. But the [compound] syllogism itself will be a propositional one and won't contain a predicative syllogism, at least when it is put in the natural and convenient way. Of the two propositional syllogisms in it, the first is recombinant and has a premise consisting of a meet-like propositional compound with overlapping antecedent and consequent. The second [of the two propositional syllogisms] is a propositional meet-like duplicative syllogism. In this form the [syllogism of] absurdity is complete - there is no need for any contrived and elaborate explanation, rounding it out with goodness knows how many syllogisms, in order to give an analysis of the complete form of the syllogism of absurdity. There is no need for the kind of lengthy exposition of [this syllogism] that one finds in the textbooks.

[8.3.2] The right way to look at it, which is how the the First Teacher 408.12 approached it, is as follows. Suppose for example that we take the goal to be

(22) Not every $C$ is a $B$.

Now we say:

(23) If the sentence 'Not every $C$ is a $B$ ' is false, then every $C$ is a $B$. 
Then we add to it a true premise:

Every $B$ is an $A$.

We have here one of the recombinant syllogisms that we counted as propositional, with the conclusion

(25) If the sentence 'Not every $C$ is a $B^{\prime}$ ' is false then every $C$ is an $A$.

Then we say:

(26) But not every $C$ is an $A$.

and in this way we get an impossible absurdity. Thus the second clause [of (25] has been duplicated as its contradictory negation, so that the contradictory negation of the first clause [of 25] follows, namely

(27) Not every $C$ is a $B$.

This is plain sailing.

[8.3.3] This compound syllogism in its complete form consists of two 409.3 syllogisms. Each of the syllogisms has a premise that is a propositional compound. The first of these two [premises] takes the same form regardless of the topic, in the sense that its first clause expresses that the goal is false and its second clause is the contradictory negation of the goal. In the second [of these two premises], the first clause always takes the same form, but the form of the second clause varies. In fact its first clause expresses that the goal is false. But its second clause takes whatever form follows if we take as premise pair the contradictory negation of the goal and the [given] true premise. One kind of premise pair entails a predicative sentence; [this is used] when the goal is predicative. Alternatively the premise pair entails a propositional compound, when the goal was a propositional compound.

[8.3.4] As we said after the claim, it goes like this:

If it is not the case that when $\phi$ then $\psi$, then it is not the case that whenever $\phi$ then $\psi$.

and:

Whenever $\chi$ then $\psi$. 
There follows:

If it is not the case that when $\phi$ then $\psi$, then it is not the case that when $\phi$ then $\chi$.

But this, namely

(31) it is not the case that whenever $\phi$ then $\chi$.

gives an absurdity. It follows that

Whenever $\phi$ then $\psi$.

This is how to analyse the syllogism known as 'by absurdity, [arguing] to- 409.13 wards its premises'.

[8.3.5] There are people who try to posit the first propositional com- 409.14 pound, and then prove the absurdity from it, saying 'But its second clause 409.15 is impossible'. In fact they reckon that

(33) The second clause is impossible.

is what has to be proved. One of them goes to great trouble to find a syllogism which brings together the second clause and impossibility. He says:

The second clause and something true combine to make a syllogism that proves an impossibility; so the conjunction of the second clause and a truth is an impossibility.

Then he produces a syllogism that proves the minor premise, and he says:

The second clause combines with etc. etc. to make a syllogism which proves an impossibility; what we get by combining it with etc. is a syllogism which proves an impossibility. So the second clause combines with a truth to give a syllogism that proves an impossibility.

This is after unification of the premises has taken place! It takes him a lot 410.1 of elaborate explanation and lengthy discussion to get to the impossibility.

[8.3.6] And one of them avoids this. He takes a premise-pair consisting 410.3 of the second clause and something true, which entails an impossibility. Then he reconsiders and says:

This conclusion is an impossibility, so [the impossibility] comes either from the major premise, or from the minor, or from the premise-pair. 
Then he uses a duplicative argument: it doesn't come from the premisepair, and this implies that it comes either from the major premise or from the minor. Then he uses another duplicative argument: it doesn't come from the major premise, since the major premise is true, so this implies that it comes from the minor premise. Then he says: the minor premise is impossible, and this implies that the contradictory negation of the second clause is true and the contradictory negation of the first clause is true. But all of these kinds of mutilation, and [these] things that are hidden and not explicit, lengthen the discussion but give us no new information. [By contrast] the account we have given is exactly the absurdity syllogism itself, no more and no less.

[8.3.7] The usual way to use absurdity is to use the recombinant [syllogism], and then you leave its [real] conclusion unmentioned; instead one mentions what is in reality a duplicate of the contradictory negation of its second clause, [and adds]

(37) So the goal is proved.

For example the usual way [to present an argument from absurdity] is to say

If [it's not the case that] not every $C$ is a $B$, then every $C$ is a $B$.

(38) But every $B$ is an $A$, so every $C$ is an $A$, and this is impossible. Hence [not] every $C$ is a $B$.

Thus when one says "so every $C$ is an $A$ ", this means

If [it's not the case that] not every $C$ is a $B$, then every $C$ is an $A$.

[In other words,] if the case is as we described, then every $C$ is an $A$. And his statement "This is impossible" means

Not every $C$ is an $A$.

- which duplicates the contradictory negation of the second clause [of (39)]. So the usual style agrees with our analysis of the absurdity syllogism.

[8.3.8] The phrase 'syllogism of absurdity' means a syllogism in which the argument reaches an impossibility, so the word 'absurdity' (kalf) refers to impossibility. Some people say that the syllogism of absurdity is called kulf. These people are out of line; $k$ ulf is just about promises. Also some 
people have said that it is just called syllogism of kalf because it approaches the [goal] from behind it ( $\mathrm{kalfih}$ ) and not through the front door - since it approaches by way of the contradictory negation of the goal. But it seems to me that the most realistic [explanation] is that kalf is used here in the sense of impossibility, not in any other sense.

\section{Notes on Qiȳās viii.3}

408.4 'The syllogism of absurdity': Read wa-qiyāsu l-kֵalfi.

408.9 'unconvincing elaboration': Read takalluf with two mss.

408.12 'how the First Teacher approached it': The First Teacher is Aristotle. There is no evidence in Aristotle's text to support Ibn Sīnā's attribution of this view to Aristotle. This is one of a number of places where Ibn Sīnā apparently assumes that Aristotle was such a good logician that he must have shared Ibn Sīnā's own insights.

409.2 For 'anna kulla read 'an laysa kullu, following ms sā.

[8.3.4] The translation uses the following abbreviations: $\phi=' \mathrm{~J}$ is $\mathrm{D}^{\prime}, \psi=$ ' $\mathrm{H}$ is $\mathrm{Z}^{\prime}, \chi={ }^{\prime} \mathrm{I}$ is $\mathrm{U}^{\prime}$.

409.3f 'syllogisms': Ibn Sīnā is careless about distinguishing simple syllogisms (one step) from compound syllogisms (more than one). From the context it seems that the second syllogism here is simple, but the first could be compound.

410.13 '[it's not the case that]': There are a couple of 'not's missing in all the manuscripts. It could be for example that there should be $m \bar{a}$ before kāna, and then laysa before kullu $j b$. This is unwelcome evidence of the logical incompetence of some very early copyist. 
411.3 'promises': Ibn Manzūur Lisān al- ${ }^{c} a r a b$ sv. klf explains knulf as a verbal noun from 'aklafa 'to default (on a promise)'. See Zimmermann [23] p. 198 footnote 6 for evidence that the reductio syllogism was vowelled kalf in the 10th century. But Zimmermann seems to accept the derivation from 'behind', which Ibn Sīnā rejects.

\section{References}

[1] Augustus De Morgan, The Connexion of Number and Magnitude: An Attempt to Explain the Fifth Book of Euclid, Taylor and Walton, London 1836.

[2] R. O. Besthorn and J. L. Heiberg, Codex Leidensis 339, 1: Euclidis Elementa Ex Interpretatione Al-Hadschdschadschii cum Commentariis AlNarizii, Hegel and Son, Copenhagen 1893.

[3] Gottlob Frege, Grundgesetze der Arithmetik I, Pohle, Jena 1893.

[4] Gottlob Frege, 'Über die Grundlagen der Geometrie', Jahresbericht der Deutschen Mathematikervereinigung 15 (1906) 293-309, 377-403, 423430.

[5] Gottlob Frege, Nachgelassene Schriften, ed. Hans Hermes et al., Meiner, Hamburg 1969.

[6] Dimitri Gutas, Avicenna and the Aristotelian Tradition: Introduction to Reading Avicenna's Philosophical Works, Brill, Leiden 1988.

[7] Wilfrid Hodges, 'The laws of distribution for syllogisms', Notre Dame Journal of Formal Logic 39 (1998) 221-230.

[8] Wilfrid Hodges, 'Tarski's theory of definitions', in New Essays on Tarski and Philosophy, ed. Douglas E. Patterson, Oxford University Press, Oxford 2008, pp. 94-132.

[9] Wilfrid Hodges, 'Traditional logic, modern logic and natural language', Journal of Philosophical Logic 38 (2009) 589-606.

[10] Wilfrid Hodges, 'Handout for: Reconciling Greek mathematics and Greek logic - Galen's question and Ibn Sina's answer', for talk in Groningen, November 2011, http://wilfridhodges.co.uk/history19a.pdf. 
[11] Wilfrid Hodges, 'Ibn Sina, Frege and the grammar of meanings', AlMukhatabat 5 (2013) 29-60.

[12] Wilfrid Hodges, 'Notes on the history of scope', to appear in Logic Without Borders: Essays in Honour of Jouko Väänänen, ed. Roman Kossak et al.

[13] Ibn Sīnā, Al-Madkhal, ed. Ibrahim Madkour et al., Cairo 1952.

[14] Ibn Sīnā, Al-Qiyās, ed. Ibrahim Madkour et al., Cairo 1964.

[15] Ibn Sīnā, Al-Burhān, ed. Ibrahim Madkour et al., Cairo 1956.

[16] Ibn Sīnā, Al-Safsata, ed. Ibrahim Madkour et al., Cairo 1958.

[17] Ibn Sīnā, Al-Najāt, ed. A. Daneshpazuh, Tehran University Press, Tehran 1985; trans. by Asad Q. Ahmed, Avicenna's Deliverance: Logic, Studies in Islamic Philosophy, Oxford University Press, Oxford 2011.

[18] Ibn Sīnā, Manțiq al-Mašriqiyyīn, Al-Maktaba al-Salafiyya, Cairo 1910.

[19] Ibn Sīnā Al-'Išārāt wal-Tanbīhāt, ed. Mojtaba Zāree ${ }^{c} \overline{1}$, Būstān-e Ketab-e Qom, Qum, Iran 2000; logic part trans. Shams C. Inati, Ibn Sīnā Remarks and Admonitions, Part One: Logic, Pontifical Institute of Mediaeval Studies, Toronto Ontario 1984.

[20] Ibn Sīnā, The Life of Ibn Sina, ed. William E. Gohlman, State University of New York Press, Albany NY 1974.

[21] John Marenbon (ed.), The Oxford Handbook of Medieval Philosophy, Oxford University Press, Oxford 2012.

[22] Alfred Tarski, 'Sur les ensembles définissables de nombres réels I', Fundamenta Mathematicae 17 (1931) 210-239.

[23] F. W. Zimmermann, Al-Farabi's Commentary and Short Treatise on Aristotle's De Interpretatione, British Academy and Oxford University Press, Oxford 1981. 